\title{
Antimicrobial activity of seven metallic compounds against penicillinase producing and non-penicillinase producing strains of Neisseria gonorrhoeae
}

\author{
M PEETERS,* D VANDEN BERGHE,* AND A MEHEUS $\dagger$ \\ From the Departments of *Microbiology and $†$ Epidemiology and Social Medicine, University of Antwerp, Antwerp, \\ Belgium
}

SUMMARY The in vitro activity of seven metallic compounds was tested against penicillinase (B lactamase) producing strains of Neisseria gonorrhoeae (PPNG) and non-PPNG strains.

On a weight basis, the mercurials showed the greatest in vitro activity. Phenylmercuric borate, thiomersal, and mercuric chloride inhibited $90 \%$ of all strains at concentrations of $5 \mathrm{mg} / 1,5 \mathrm{mg} / 1$, and $20 \mathrm{mg} / 1$ respectively. Silver nitrate inhibited $90 \%$ of the strains at $80 \mathrm{mg} / 1$ and the $\mathrm{MIC}_{90}$ for mild silver protein was $200 \mathrm{mg} / 1$. Copper and selenium salts had lower in vitro activities, inhibiting $90 \%$ of all the strains at $320 \mathrm{mg} / 1$ and $640 \mathrm{mg} / 1$ respectively. Silver nitrate and the six other compounds tested showed equal activities against PPNG and non-PPNG strains. This finding supports the recommendation for prophylaxis of gonococcal conjunctivitis of the newborn with $1 \%$ silver nitrate eye drops.

\section{Introduction}

Gonococcal ophthalmia neonatorum was a leading cause of childhood blindness before the penicillin era. ${ }^{1}$ Prevention was essential. In 1881 Crédé introduced silver nitrate for prophylaxis, and its use became widespread. Where prophylaxis was implemented the incidence of blindness caused by gonococcal ophthalmia neonatorum decreased dramatically. The transient chemical conjunctivitis that occurs in up to half the of neonates given $1 \%$ silver nitrate eye drops caused reservations about the practice. ${ }^{2} 3$ Since the 1960 s some countries have switched from silver nitrate to antibiotics, such as tetracycline, erythromycin, or penicillin, for prophylaxis against neonatal ocular infection with Neisseria gonorrhoeae, whereas others abandoned prophylaxis. ${ }^{4}$

In 1976 infections caused by penicillinase producing strains of $N$ gonorrhoeae (PPNG) emerged and have been increasing since. ${ }^{5}$ These PPNG strains render the treatment of gonococcal ophthalmia difficult as the appropriate antibiotics, such as cefotaxime or kanamycin, ${ }^{68}$ are not widely available, particularly in developing countries. It is not known whether silver nitrate would be less effective in preventing

Address for reprints: Dr $\mathbf{M}$ Peeters, Centre International de Recherches Medicales de Franceville, BP 769, Franceville, Republic of Gabon

Accepted for publication 19 September 1985 gonococcal ophthalmia caused by PPNG strains. In this study, we tested the in vitro activity of silver nitrate and six other antimicrobial metallic compounds against PPNG and non-PPNG strains.

\section{Materials and methods}

We tested 58 strains of $N$ gonorrhoeae, 13 of which were PPNG as assessed by the chromogenic cephalosporin test. ${ }^{9}$

We measured minimum inhibitory concentrations by an agar dilution technique using GC agar base (Oxoid, Basingstoke, Hampshire, England) supplemented with $1 \%$ haemoglobin (Oxoid) and $1 \%$ IsoVitaleX (BBL). Using a multipoint replicator we inoculated suspensions of overnight cultures in $2 \mathrm{ml}$ blood-saponin broth (tryptic soy broth (Difco Laboratories, Detroit), $1 \%$ saponin (Merck, Darmstadt, Germany), and 5\% horse blood) on to plates containing twofold dilutions of the antimicrobials. The inoculum was $10^{5}$ colony forming units (cfus). The plates were incubated for 24 hours at $35^{\circ} \mathrm{C}$ in an atmosphere of $5 \%$ carbon dioxide. The MIC was the lowest concentration of the antimicrobial that inhibited visible growth.

We tested the following antimicrobial products: silver nitrate (Merck, Darmstadt, Germany), mild silver proteinate (Cooper Lab, USA), mercuric chloride (Merck), thiomersal (Federa, Brussels, Belgium), phenylmercuric borate (Sigma, St Louis, 
Missouri, USA) copper sulphate (Merck), and sodium selenite (Riedel-De Haen AG, Seelze-Hannover, Germany).

\section{Results}

The table shows the MICs of the seven antimicrobial metallic compounds for the 58 strains of $N$ gonorrhoeae. All three mercurials were highly active against all strains tested. The MICs of thiomersal and phenylmercuric borate were comparable: $90 \%$ of the strains were inhibited by $5 \mathrm{mg} / \mathrm{l}$ thiomersal and 2.5 $\mathrm{mg} / \mathrm{l}$ phenylmercuric borate respectively. The MIC of the inorganic mercury compound was higher than that of the organic compounds, probably because the free $\mathrm{Hg}++$ ions are preferentially bound to compounds of the very rich GC agar base medium. Silver nitrate showed a lower $\mathrm{MIC}_{90}(80 \mathrm{mg} / \mathrm{l})$ than mild silver proteinate $(200 \mathrm{mg} / 1)$. Copper sulphate inhibited $90 \%$ of all strains at a concentration of $320 \mathrm{mg} / 1$, and the $\mathrm{MIC}_{90}$ for sodium selenite was $640 \mathrm{mg} / \mathrm{l}$. In contrast, Haemophilus ducreyi has been shown to have a high susceptibility to sodium selenite (MIC $1 \mathrm{mg} / 1$ to 4 $\mathrm{mg} / \mathrm{l}$ ) and copper (II) chloride (MIC $2 \mathrm{mg} / 1$ to 8 $\mathrm{mg} / \mathrm{l}) .{ }^{9}$ All the products tested except sodium selenite had a very narrow range of MICs.

For all the antimicrobial metallic compounds tested, there was no difference in susceptibility between PPNG and non-PPNG strains.

\section{Discussion}

The increasing prevalence of PPNG strains, particularly in developing countries, makes it important to prevent neonatal conjunctivitis caused by Ngonorrhoeae.

TABLE Minimum inhibitory concentrations (MICs) of seven antimicrobials against 13 strains of penicillinase producing Neisseria gonorrhoeae (PPNG) and 45 non-PPNG strains

\begin{tabular}{lllllc}
\hline \multirow{2}{*}{ Product } & Strain & $\begin{array}{l}\text { Range of } \\
M I C s\end{array}$ & $\begin{array}{c}M I C_{50} \\
(m g / l)\end{array}$ & $\begin{array}{c}M I C_{90} \\
(m g / l)\end{array}$ \\
\hline Silver nitrate & Non-PPNG & 40 & -160 & 80 & 80 \\
& PPNG & 20 & -80 & 80 & 80 \\
Mild silver proteinate & Non-PPNG & 50 & -200 & 200 & 200 \\
& PPNG & 50 & -200 & 200 & 200 \\
Mercuric chloride & Non-PPNG & 10 & -20 & 10 & 20 \\
& PPNG & $10-20$ & 10 & 20 \\
Thiomersal & Non-PPNG & $1 \cdot 25-$ & 5 & $2 \cdot 5$ & 5 \\
& PPNG & $1 \cdot 25-$ & 5 & $2 \cdot 5$ & 5 \\
Phenylmercuric borate & Non-PPNG & $0 \cdot 6-$ & $2 \cdot 5$ & $2 \cdot 5$ & $2 \cdot 5$ \\
\multirow{5}{*}{ Sodium selenite } & PPNG & $1 \cdot 25-$ & 5 & $2 \cdot 5$ & 5 \\
\multirow{5}{*}{ Copper sulphate } & Non-PPNG & 20 & -1280 & 320 & 640 \\
& PPNG & 20 & -640 & 320 & 640 \\
& Non-PPNG & 80 & -320 & 320 & 320 \\
& PPNG & & 320 & 320 & 320 \\
\hline
\end{tabular}

This study shows that silver nitrate prophylaxis should be effective against PPNG and non-PPNG strains. Ophthalmic ointments containing $1 \%$ tetracycline or $0.5 \%$ erythromycin have been proposed as alternatives to the $1 \%$ silver nitrate eye drops. ${ }^{10}$ It is uncertain whether these agents are as effective as silver nitrate in areas with increasing penicillin resistance. It has been shown that PPNG strains can also be resistant to several other antibiotics, including tetracycline and erythromycin, ${ }^{11}{ }^{12}$ but not whether this in vitro resistance affects the effectiveness of topical treatment. Moreover, in developing countries keeping fresh preparations of antibiotics for ophthalmic use is difficult. For these reasons prophylaxis with silver nitrate $1 \%$ eye drops immediately after birth has been recommended in areas with considerable risk of gonococal ophthalmia neonatorum. ${ }^{713}$ An alternative prophylactic method should be effective against all gonococcal strains, particularly PPNG strains; it should have no side effects, or fewer than silver nitrate; and it should be inexpensive. Such an alternative is in fact not available. We tested the in vitro activities of other metallic compounds on Ngonorrhoeae. This study showed that several metallic compounds, in particular the organic mercurials, are highly active in vitro against $\mathrm{Ngonorrhoeae.} \mathrm{Further} \mathrm{studies} \mathrm{are} \mathrm{required} \mathrm{to}$ assess their activity against other micro-organisms, such as Chlamydia trachomatis, their cytotoxicity, and their irritating effect on the conjunctivae.

\section{References}

1. Barsam PC. Specific prophylaxis of gonorrheal ophthalmia neonatorum: a review. $N$ Engl J Med 1966;274:731-4.

2. Wahlberg V, Kallings IM, Winberg J. Epidemiological aspects of gonorrhoeal and chlamydial infections. Local effects of silver nitrate and hexarginum. Acta Paediatr Scand [Suppl] 1982;295:27-36.

3. Wishida $\mathrm{H}$, Risemberg HM. Silver nitrate ophthalmic solution and chemical conjunctivitis. Pediatrics 1975;56:368-73.

4. Oriel JD. Ophthalmia neonatorum: relative efficacy of current prophylactic practices and treatment. J Antimicrob Chemother 1984;14:209-20.

5. O'Callaghan CM, Morris A. Kirby SM, Shingler AM. Novel method for detection of beta-lactamase by using a chromogenic cephalosporin substrate. Antimicrob Agents Chemother 1972;1:283-8.

6. Meheus A, Piot P. Lutte contre les maladies sexuellement transmissibles dans les pays en developpement. Ann Soc Belg Med Trop 1983;63:281-311.

7. Working group of the World Health Organisation. Prevention and treatment of conjunctivitis in the newborn at the primary level. Geneva: World Health Organisation, 1984 (PBL/84.4).

8. Fransen L, Nsanze H, D'Costa L, Brunham RC, Ronald AR, Piot P. Single-dose kanamycin therapy of gonococcal ophthalmia neonatorum. Lancet 1984;ii:1234-7.

9. Slootmans L, Vanden Berghe D, Van Dyck E, Piot P. Susceptibility of 40 Haemophilus ducreyi strains to 34 antimicrobial products. Antimicrob Agents Chemother 1983;24:564-7.

10. Rothenberg R. Ophthalmia neonatorum due to Neisseria gonorrhoeae: prevention and treatment. Sex Transm Dis
1979;6:187-91. 
11. Siegel MS, Thornsberry C, Biddle JW, O'Hara PR, Perine PR, Wiesner PJ. Penicillinase-producing Neisseria gonorrhoeae: results of surveillance in the United States. J Infect Dis 1978:137:170-5.

12. Herzog C, Ison CA, Easmon CSF. Antimicrobial sensitivity of Neisseria gonorrhoeae: comparison of penicillinase producing and non-penicillinase producing strains. British Journal of Venereal Diseases 1983;59:289-92.
13. Galega FP, Heymann DL, Nasah BT. Gonococcal ophthalmia neonatorum: the case for prophylaxis in tropical Africa. Bull WHO 1984;62:95-8. 